\title{
Genotyping of 10 Grain Shape Genes in High Quality Xian/indica Varieties by Molecular Marker
}

Zhou Lei ${ }^{1}$, Li Erjing ${ }^{1,2}$, Xu Huashan ${ }^{1}$, Chen Zhijue ${ }^{1}$, Yang Guocai ${ }^{1}$, Liu Kai ${ }^{1}$, You Aiqing ${ }^{1,3} \square$

1 Hubei Key Laboratory of Food Crop Germplasm and Genetic Improvement, Food Crops Institute, Hubei Academy of Agricultural Sciences, Wuhan, 430064, China

2 College of Life Sciences, Wuhan University, Wuhan 430072, China

3 Hubei Collaborative Innovation Center for Grain Industry, Yangtze University, Jingzhou, 434025, China

D Corresponding author email: aq_you@163.com

Molecular Plant Breeding, 2021, Vol.12, No.29 doi: 10.5376/mpb.2021.12.0029

Received: 15 Sep., 2021

Accepted: 23 Sep., 2021

Published: 11 Oct., 2021

Copyright $\odot \mathbf{2 0 2 1}$ Zhou et al., This article was first published in Molecular Plant Breeding in Chinese, and here was authorized to translate and publish the paper in English under the terms of Creative Commons Attribution License, which permits unrestricted use, distribution, and reproduction in any medium, provided the original work is properly cited.

Preferred citation for this article:

Zhou L., Li E.J., Xu H.S., Chen Z.J., Yang G.C., Liu K., and You A.Q., 2021, Genotyping of 10 grain shape genes in high quality Xian/indica varieties by molecular marker, Molecular Plant Breeding, 12(29): 1-10 (doi: 10.5376/mpb.2021.12.0029)

\begin{abstract}
Seven grain length genes including GS3, LGY3, qGL3, GL7, SLG7, TGW6 and GS9, and three grain width genes including GW8, GW5 and GS5 were tested by molecular marker. The results showed that: All 12 varieties have the gs3 long-grain allele, Ezhong 5, Yujing 91, Yuzhenxiang, Huangmaozhan, Yangxizao and Super-Basimati have the $G L 7$ and $S L G 7$ long-grain allele, 11 varieties with the exception of Jianzhen 2 have the $g w 8$ slender-grain allele, Yujing 91, Yuzhenxiang, 9311, R835, Huangmaozhan, Yangxizao have the GS5 Wide-grain allele. This study is helpful to establish an overall understanding of the genotypes of 10 grain-shape genes in high quality xian/indica varieties, and provides important genotype information in selecting and cultivating new high quality long-grain indica varieties via molecular marker-assisted selection in the future.
\end{abstract}

Keywords High quality xian/indica rice; Grain shape gene; Molecular marker; Genotype

Rice is the most important crop in China, the production and the consumption of which is the highest in the world. For a long period in the last century, owing to lack of food, people took yield as the only goal of rice breeding, but ignored its quality. Since the beginning of this century, the production of rice, wheat, corn and other grains has all improved. With the continuous improvement of people's living standards and the increasing competition in the international and domestic markets, the problem of poor quality of rice in China has become increasingly prominent, which is becoming the main bottleneck of the current rice industry (Wan and You, 2018).

High quality rice in China accounts for more than $10 \%$ of the market, and Hubei Province can plant at least 3 million mu. But the four varieties with the largest promotion area, Ezhong No. 5, Jianzhen No. 2, Yuzhenxiang, and Exiang No. 2, have planted less than 1 million mu totally. It can be seen that the supply of high quality rice varieties is far from meeting the demand for the development of production, which has become the bottleneck of industrialization development of high quality rice. After nearly 20 years' scientific research, some high quality rice varieties had bred by Chinese rice breeders and been approved, such as the high quality xian/indica rice, Ezhong No. 5 , cultivated by our unit, whose chalky rice rate and chalkiness degree were is double 0 . Except the amylose content, the other indexesall reached the first grade of National standard, the taste score remained above 85, and it was examined and approved in Hubei and Hainan Province (Li et al., 2005) The quality of Ezhong No. 5 is equivalent to that of Thai fragrant rice. It has become the first choice for large rice processing enterprises such as "Guobao Qiaomi" and "Wacang Dami" in Hubei Province to develop high quality rice and build famous brands.

At present, the generally recognized high quality xian/indica rice refers to a type that has crystal-clear appearance, slender grain, excellent physical and chemical indicator, and high taste score, which is comparable to Thai fragrant rice. High quality xian/indica rice requires not only the improvement of physical and chemical indicators, but also the appearance and taste. The grain shape traits not only affect the yield, but also affect the quality, mainly including grain length, grain width and L/W Ratio (Gao et al., 2011). The grain shape traits are closely related to 
the appearance and milling quality of rice, and also affect the thousand-grain weight. Therefore, studying the heredity and molecular mechanism of rice grain shape and applying it to breeding practice will help to improve the yield and quality (Luo et al., 2004; Huang and Qian, 2017). In order to analyze the genetic basis of grain length traits of high quality rice, this study collected 12 high quality xian/indica rice varieties, and used molecular marker methods to detect and analyze 10 cloned rice grain-type genes. This study not only has a comprehensive understanding of the genotypes of long-grain xian/indica rice varieties, but also provides scientific basis to breed new high quality xian/indica rice varieties by using molecular marker methods in the future.

\section{Results and Analysis}

\subsection{Analysis of grain shape traits of 12 high quality xian/indica rice}

The grain length of 12 high quality xian/indica rice varieties is $7.36 \sim 11.93 \mathrm{~mm}$, the grain width is $2.10 \sim 2.73 \mathrm{~mm}$, and the L/W Ratio is 2.70 5.29 $\mathrm{mm}$ (Table 1). The t-test results showed that, contrasting 9311, the grain length and L/W Ratio of high quality rice, Ezhong No. 5, Yujing 91, Yuzhenxiang, Huangmaozhan and Super-Basmati are larger than 9311, and the difference is extremely significant $(\mathrm{P}<0.01)$; The grain length of Xiang 5, 15Q340, Yangxizao, Huarun 2 and Jianzhen 2 are not significantly different from 9311; The grain length and L/W Ratio of R835 are significantly less than 9311 . The results showed that, according to the $\mathrm{L} / \mathrm{W}$ Ratio, these 12 high quality xian/indica rice varieties can be divided into three types: super long grain $(>4.0)$, general long grain $(>3.0$ and $<4.0$ ), and medium and short grain (<3.0). Ezhong No. 5, Yujing 91, Yuzhenxiang, Huangmaozhan, Yangxizao and Super-Basmati belong to super long grain. R835 belongs to medium and short grain. 9311 and other five varieties belong to general long grain.

Table 1 Measurement of grain shape of 12 high quality xian/indica varieties

\begin{tabular}{llll}
\hline Accessions & Length $(\mathrm{mm})$ & Width $(\mathrm{mm})$ & L/W Ratio \\
\hline 9311(CK) & 9.5 & 2.5 & 3.8 \\
Ezhong 5 & 11.1 & 2.3 & 4.8 \\
Yujing 91 & 11.9 & 2.6 & 4.6 \\
Yuzhenxiang & 11.7 & 2.4 & 4.9 \\
Xiang 5 & 9.1 & 2.5 & 3.6 \\
15Q340 & 9.7 & 2.6 & 3.7 \\
R835 & 7.4 & 2.9 & 2.5 \\
Huangmaozhan & 11.7 & 2.2 & 5.3 \\
Yangxizao & 10.2 & 2.3 & 4.4 \\
Huarun 2 & 9.3 & 2.4 & 3.9 \\
Super-Basimati & 10.9 & 2.2 & 5.0 \\
Jianzhen 2 & 9.7 & 2.4 & 3.9 \\
\hline
\end{tabular}

\subsection{Genotype analysis}

$G S 3$ is the first gene to be cloned to regulate grain shape, which mainly regulates rice grain length and weight. When a C-A mutation in the second exon caused a loss-of-function mutation in the N-terminal domain that regulates organ size, the rice grains became longer. Fan et al. (2009) designed primers SF28F/SF28R (Table 2) based on this site to amplify the genomic DNA of rice material, and a $136 \mathrm{bp}$ target fragment could be obtained. The fragment of short grain allele produced two segments, $110 \mathrm{bp}$ and $26 \mathrm{bp}$, after Pst I digestion. While due to the C-A mutation, the $136 \mathrm{bp}$ produced by the long-grain allele cannot be digested by Pst I. Only the genotypes of japonica rice, referring to Nipponbare, could be digested by Pst I (Figure 1), and 110 bp bands containing GS3 gene appeared. None of the tested 12 xian/indica rice varieties could be recognized and digested by Pst $\mathrm{I}$, and they all contained the long-grain $g_{s} 3$ allele. 
Molecular Plant Breeding 2021, Vol.12, No.29, 1-10

http://genbreedpublisher.com/index.php/mpb

Table 2 Functions markers for rice grain shape gene

\begin{tabular}{|c|c|c|c|c|c|}
\hline Marker & Primer Sequence & Type & Polymorphic site & $\begin{array}{l}\text { PCR product } \\
\text { size (bp) }\end{array}$ & Reference \\
\hline $\begin{array}{l}\text { SF28F } \\
\text { SF28R }\end{array}$ & $\begin{array}{l}\text { F:TGCCCATCTCCCTCG } \\
\text { TTTAC } \\
\text { R:GAAACAGCAGGCT } \\
\text { GGCTTAC }\end{array}$ & CAPs-Pst I & C/A substitution in Exon-2 & $136 / 110$ & Fan et al., (2009) \\
\hline $\begin{array}{l}\lg 3 F \\
\lg 3 R\end{array}$ & $\begin{array}{l}\text { F:CCTGACAATAATTCG } \\
\text { CCCAATA } \\
\text { R:CGTAAGAGAGCACG } \\
\text { CACGTA }\end{array}$ & InDel & InDel between Exon- 8 and Intron-9 & 392 & Liu et al., (2018) \\
\hline $\begin{array}{l}\text { GL3F } \\
\text { GL3R }\end{array}$ & $\begin{array}{l}\text { F:CGATTCTATCTGGTT } \\
\text { CAGTGGTAGA } \\
\text { R:CACCGCCGTGTAAG } \\
\text { TTCAAC }\end{array}$ & dCAPs- $A c c$ I & $\mathrm{A} / \mathrm{C}$ substitution in Exon-10 & $139 / 118$ & Yi et al., (2016a) \\
\hline $\begin{array}{l}\text { NGSP11F } \\
210 Q C F\end{array}$ & $\begin{array}{l}\text { F:TGACACGCCACAGT } \\
\text { CCAAGACGAGCAGT } \\
\text { R:AAGGGAGTTGAGA } \\
\text { GTAGAAAAAA }\end{array}$ & InDel & $17.1 \mathrm{~Kb}$ duplication & 1421 & Wang et al., (2015b) \\
\hline $\begin{array}{l}\text { SLG7F } \\
\text { SLG7R }\end{array}$ & $\begin{array}{l}\text { F:CCATACCACATCTCA } \\
\text { TCTCAC } \\
\text { R:GCTCACGCACATCC } \\
\text { AACT }\end{array}$ & InDel & $11 \mathrm{bp}$ delete in promoter at $-104 \mathrm{bp}$ & $109 / 98$ & Zhou et al., (2015) \\
\hline $\begin{array}{l}\text { CAPS6-1F } \\
\text { CAPS6-1R }\end{array}$ & $\begin{array}{l}\text { F:CCACAGCCACAACG } \\
\text { AGAAT } \\
\text { R:ACCGTTCGGGTAGG } \\
\text { TTATGT }\end{array}$ & CAPs-BssH II & 1 bp delete $(\mathrm{G})$ at $313 \mathrm{bp}$ & $590 / 372 / 217$ & Wang et al., (2014) \\
\hline $\begin{array}{l}\text { GS9F } \\
\text { GS9R }\end{array}$ & $\begin{array}{l}\text { F:CTCGCTTTCTTTACC } \\
\text { TATGTTCAAGCCTTC } \\
\text { R:GAAACTGTTGCCTT } \\
\text { TGCTCTTGTCT }\end{array}$ & InDel & $7 \mathrm{~Kb}$ insert & 250 & Zhao et al., (2018) \\
\hline $\begin{array}{l}\text { GW5-1F } \\
\text { GW5-1R }\end{array}$ & $\begin{array}{l}\text { F:AGTACGACCATGAT } \\
\text { GTTTCCC } \\
\text { R:GACCTAACCCATCT } \\
\text { CATTCCA }\end{array}$ & InDel & 1212bp InDel & 775 & Weng et al., (2008) \\
\hline $\begin{array}{l}\text { GW8-1F } \\
\text { GW8-1R }\end{array}$ & $\begin{array}{l}\text { F:AAAGAGACAGCCAC } \\
\text { GGAATC } \\
\text { R:ATCTTGAGATCCCA } \\
\text { CTCCATG }\end{array}$ & InDel & $10 \mathrm{bp}$ InDel in promoter & $151 / 141$ & Yi et al., (2016b) \\
\hline $\begin{array}{l}\text { GW8-2F } \\
\text { GW8-2R }\end{array}$ & $\begin{array}{l}\text { F:AGGCGAGATCAGCT } \\
\text { TCGTCA } \\
\text { R:GCTACCGTCTTCAG } \\
\text { AAGTGGC }\end{array}$ & $\begin{array}{l}\text { dCAPs-Hind } \\
\text { II }\end{array}$ & $\mathrm{A} / \mathrm{C}$ substitution in Exon-3 & $108 / 89$ & \\
\hline $\begin{array}{l}\text { GW8-3F } \\
\text { GW8-3R }\end{array}$ & $\begin{array}{l}\text { F:ATGTTCTCCGATGGT } \\
\text { GGGTT } \\
\text { R:TGAAGGCCAGAGAT } \\
\text { GAGAGG }\end{array}$ & CAPs-Nco I & G/T substitution in Exon-3 & $164 / 134$ & \\
\hline $\begin{array}{l}\text { GS5-1F } \\
\text { GS5-1R }\end{array}$ & $\begin{array}{l}\text { F:GCAAGACAAGGAG } \\
\text { CAGCACTA } \\
\text { R:AGAAGCCGACCCCA } \\
\text { ACAG }\end{array}$ & CAPs-Dde I & CTA/ACC substitution in Exon-2 & $225 / 196$ & Yi et al., (2016c) \\
\hline $\begin{array}{l}\text { GS5-2F } \\
\text { GS5-2R }\end{array}$ & $\begin{array}{l}\text { F:CAGTTCTCGGTACT } \\
\text { GCGTCGA } \\
\text { R:CACAAACCTCCCAG } \\
\text { CAACC }\end{array}$ & dCAPs-Sal I & A/C substitution in Exon-9 & $188 / 169$ & \\
\hline
\end{tabular}




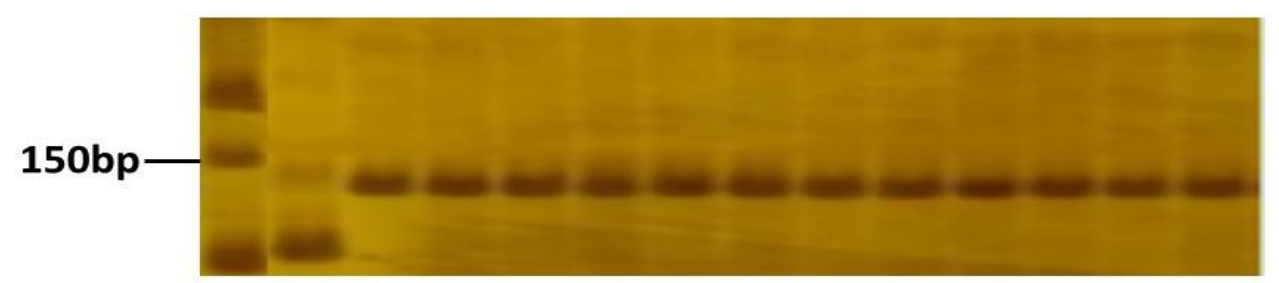

\section{$\begin{array}{llllllllllllll}M & P & 1 & 2 & 3 & 4 & 5 & 6 & 7 & 8 & 9 & 10 & 11 & 12\end{array}$}

Figure $1 G S 3$ genotypic analysis of high quality xian/indica varieties (after Pst digestion)

Note: M: DL500 DNA Marker; P: Nipponbare; Lane 1 12: Ezhong 5, Yujing 91, Yuzhenxiang, Xiang5, 9311, 15Q340, R835, Huangmaozhan, Yangxizao, Huarun 2, Super-Basmati, Jianzhen 2

The $L G Y 3 / O s L G 3 b$ gene encodes a transcription factor OsMADS1 containing the MADS domain, which is a key effector of the downstream of the G protein $\beta \gamma$ dimer (Liu et al., 2018; Yu et al., 2018). The LGY3 allele has a deletion between the $8^{\text {th }}$ intron and the $9^{\text {th }}$ exon, and makes (TCCTTGGTGAAGGTA) insert (ATGTATATATACT), resulting in a loss-of-function mutation, which increases the grain length of rice. The primers lgy3F/lgy3R were designed according to the mutation site to amplify the selected rice material. If there is no mutation, a $392 \mathrm{bp}$ sequence can be amplified. If it becomes a long-grain allele after mutation, no band will appear. The experimental results showed that all the 12 tested xian/indica rice varieties could amplify a $392 \mathrm{bp}$ sequence, and all of them contained the $L G Y 3$ short-grain allele.

\subsection{Genotype analysis of $q G L 3 / G L 3.1 / q G L 3-1$}

$q G L 3 / G L 3.1 / q G L 3-1$ is a gene that controls grain length on the third chromosome of rice. It was reported by three laboratories in China in 2012 that $q G L 3 / G L 3.1 / q G L 3-1$ plays a role as a negative regulator in the regulation of rice grain length (Yi et al., 2016a). In the $10^{\text {th }}$ exon of this gene, there is an $\mathrm{A} / \mathrm{C}$ mutation site, which is related to the grain length of rice. The average grain length of genotype A exceeds the average grain length of genotype Yi et al. (2016a) developed a molecular marker for $q G L 3$ based on this mutation site. If the genotype is A, the generated $139 \mathrm{bp}$ target fragment cannot be recognized and digested by Acc I enzyme; The genotype $\mathrm{C}$ can be recognized and digested by Acc I enzyme, resulting in two bands, $118 \mathrm{bp}$ and $21 \mathrm{bp}$. The results of PAGE gel electrophoresis showed that all the 12 tested xian/indica rice varieties could be recognized and digested by Acc I, and all were judged to be $\mathrm{C}$ genotypes, which belonged to the varieties without $q G L 3 / G L 3.1 / q G L 3-1$ long-grain allele.

GL7 is a gene that controls grain length on the $7^{\text {th }}$ chromosome of rice. It encodes a protein homologous to Arabidopsis long leaf protein and regulates the longitudinal elongation of cells. The tandem duplication of a 17.1 $\mathrm{kb}$ fragment at the $G L 7$ site leads to up-regulation of $G L 7$ and the down-regulation of nearby negative regulators, resulting in the increase of grain length and the improvement of appearance quality. Wang et al. (2015b) designed primers based on this mutation site. If there is a $17.1 \mathrm{~kb}$ tandem repeat in the detected rice material, a $1.4 \mathrm{~kb}$ fragment can be amplified during PCR; if not, no amplification products will appear after PCR. Ezhong No. 5, Yujing 91, Yuzhenxiang, Huangmaozhan, Yangxizao, and Super Basmati can amplify a $1.4 \mathrm{~kb}$ fragment, which are judged to contain the GL7 long-grain allele. Xiang 5, 9311, 15Q340, R835, Huarun 2 and Jianzhen 2 have bands, which are judged to contain no $G L 7$ long-grain allele (Figure 2).

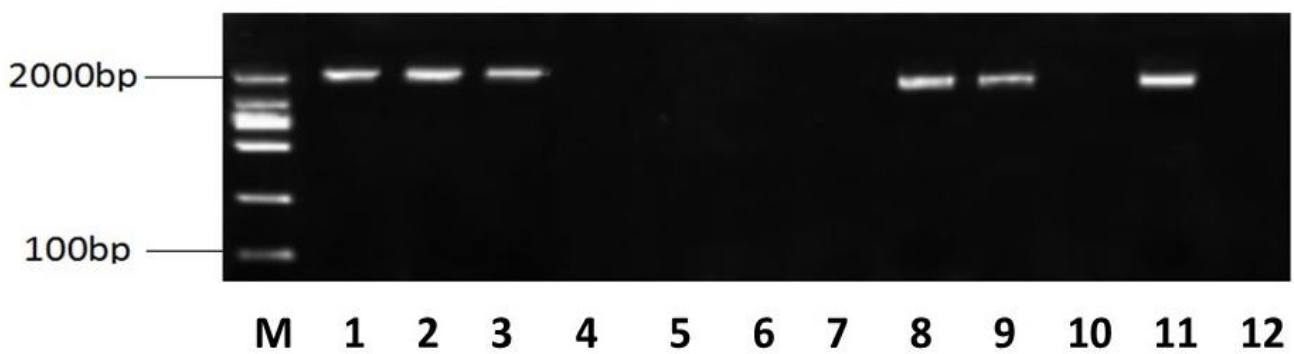

Figure 2 GL7 genotypic analysis of high quality xian/indica varieties

Note: M: DL500 DNA Marker; Lane 1 12: Ezhong 5, Yujing 91, Yuzhenxiang, Xiang5, 9311, 15Q340, R835, Huangmaozhan, Yangxizao, Huarun 2, Super-Basmati, Jianzhen 2 
$S L G 7 / G W 7$ is a gene that controls grain length on the $7^{\text {th }}$ chromosome of rice (Wang et al., 2015a; Zhou et al., 2015). By comparison, it was found that the deletion of $11 \mathrm{bp}$ at the long-grain allele promoter -104 bp is closely linked to the grain shape, and the InDel molecular marker M-SLG7 was developed based on this site. We using the marker to amplify rice material, the insertion and deletion of $11 \mathrm{bp}$ could be identified by PAGE electrophoresis. The material containing $11 \mathrm{bp}$ can amplify a $109 \mathrm{bp}$ DNA fragment, while the material without 11 bp can amplify a 98 bp fragment. The results showed (Figure 3), Ezhong 5, Yujing 91, Yuzhixiang, Huangmaozhan, Yangxizao and Super Basmati amplified 98 bp fragments, indicating that they contain the SLG7 long-grain allele and other varieties amplified $109 \mathrm{bp}$ fragments, indicating that they do not contain the $S L G 7$ long-grain allele.

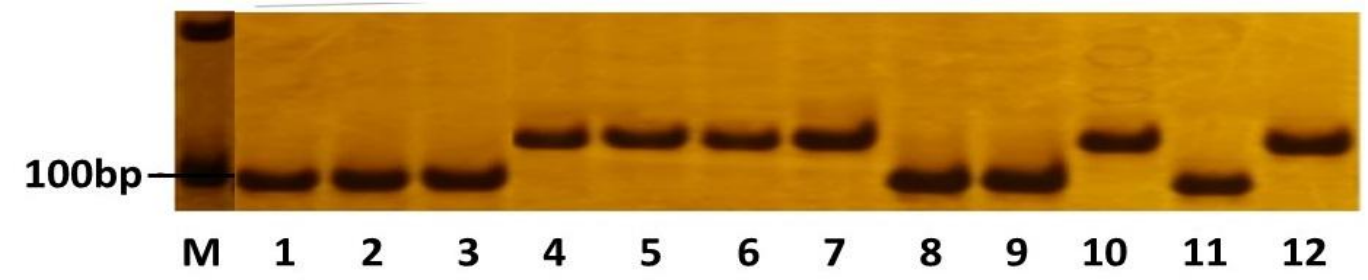

Figure 3 SLG7 genotypic analysis of high quality xian/indica varieties

Note: M, DL500 DNA Marker; Lane 1 12: Ezhong 5, Yujing 91, Yuzhenxiang, Xiang5, 9311, 15Q340, R835, Huangmaozhan, Yangxizao, Huarun 2, Super-Basmati, Jianzhen 2

TGW6 is a gene that controls grain length and thousand-grain weight on the $6^{\text {th }}$ chromosome of rice. It encodes IAA-glucose hydrolase and has only one exon but no introns. Wang et al. (2014) designed a CAPS-BssH II marker and amplified the rice genome with this marker to obtain a $590 \mathrm{bp}$ target fragment. The long-grain allele can be recognized by $B s s \mathrm{H}$ II and digested to produce two bands, $372 \mathrm{bp}$ and $217 \mathrm{bp}$, while the PCR product of the short-grain allele cannot be digested by the $B s s \mathrm{H}$ II restriction endonuclease. The results showed that the 12 tested xian/indica rice varieties cannot be digested by Bss $\mathrm{H}$ II, and it was judged that none of them contains the TGW6 long-grain allele.

GS9 is a gene that controls grain length on the $9^{\text {th }}$ chromosome of rice and encodes a protein with no known conserved functional domains. It is a transcriptional activator that regulates rice grain shape and appearance quality. Zhao et al. (2018) developed the InDel molecular marker based on the insertion of $7 \mathrm{~kb}$ at the second exon of the polymorphic site. GS9 short-grain allele has no insertion of $7 \mathrm{~kb}$ fragment and about $250 \mathrm{bp}$ fragment can be obtained by PCR. The GS9 long-grain allelic has insertion of $7 \mathrm{~kb}$ fragment and will not produce about $250 \mathrm{bp}$ fragment. The products were detected by agarose electrophoresis, and the results showed that the products were all about $250 \mathrm{bp}$, indicating that the 12 tested xian/indica rice varieties don't contain GS9 long-grain allele.

GW5 is a gene that controls grain width on the $5^{\text {th }}$ chromosome of rice. Compared with narrow-grain rice, wide-grain varieties have a $1.2 \mathrm{~kb}$ deletion in nucleotides. Based on this $1.2 \mathrm{~kb}$ deletion, an Indel marker was designed (Weng et al., 2008). Using this primer to amplify the tested rice material, we found that there is no PCR product after PCR for wide-grain allele varieties, while the amplified product of narrow-grain allele is $775 \mathrm{bp}$ fragment. The test results showed that none of the 12 xian/indica rice varieties had a $1.2 \mathrm{~kb}$ nucleotide deletion, indicating that they don't contain the GW5 wide-grain allele.

GW8 is a gene that controls grain width on the $8^{\text {th }}$ chromosome of rice. Yi et al. (2016b) developed functional markers (GW8-1), dCAPs (GW8-2) and CAPs (GW8-3) according to the $10 \mathrm{bp}$ Indel in the gene promoter region and the 2 missense sites of the third exon A/C and T/G. And according to these 3 mutation sites, the gene is divided into 8 haplotype (called Hap for short). The grain lengths of Hap1, Hap2, Hap3, and Hap7 are longer than those of Hap4, Hap5, and Hap6. For GW8-1 primers, if there is a $10 \mathrm{bp}$ sequence insert fragment in the tested rice material, a $151 \mathrm{bp}$ fragment will be generated after PCR, while if there is no $10 \mathrm{bp}$ sequence insert fragment, a 141 bp fragment will be generated. The result shows (Figure 4) that the three detection sites of Jianzhen No. 2 belong to $10 \mathrm{bp}-, \mathrm{C}$, and $\mathrm{G}$ alleles, which belong to the wide-grain haplotype, Hap6. The three detection sites of 15Q340 and Super Bassi belong to $10 \mathrm{bp}+, \mathrm{C}$ and $\mathrm{T}$ alleles, which belong to the slender-grain haplotype, Hap1. And the 
three detection sites of the other nine varieties belong to $10 \mathrm{bp}+, \mathrm{A}$, and $\mathrm{T}$ alleles, which belong to the elongated-grain haplotype, Hap3.

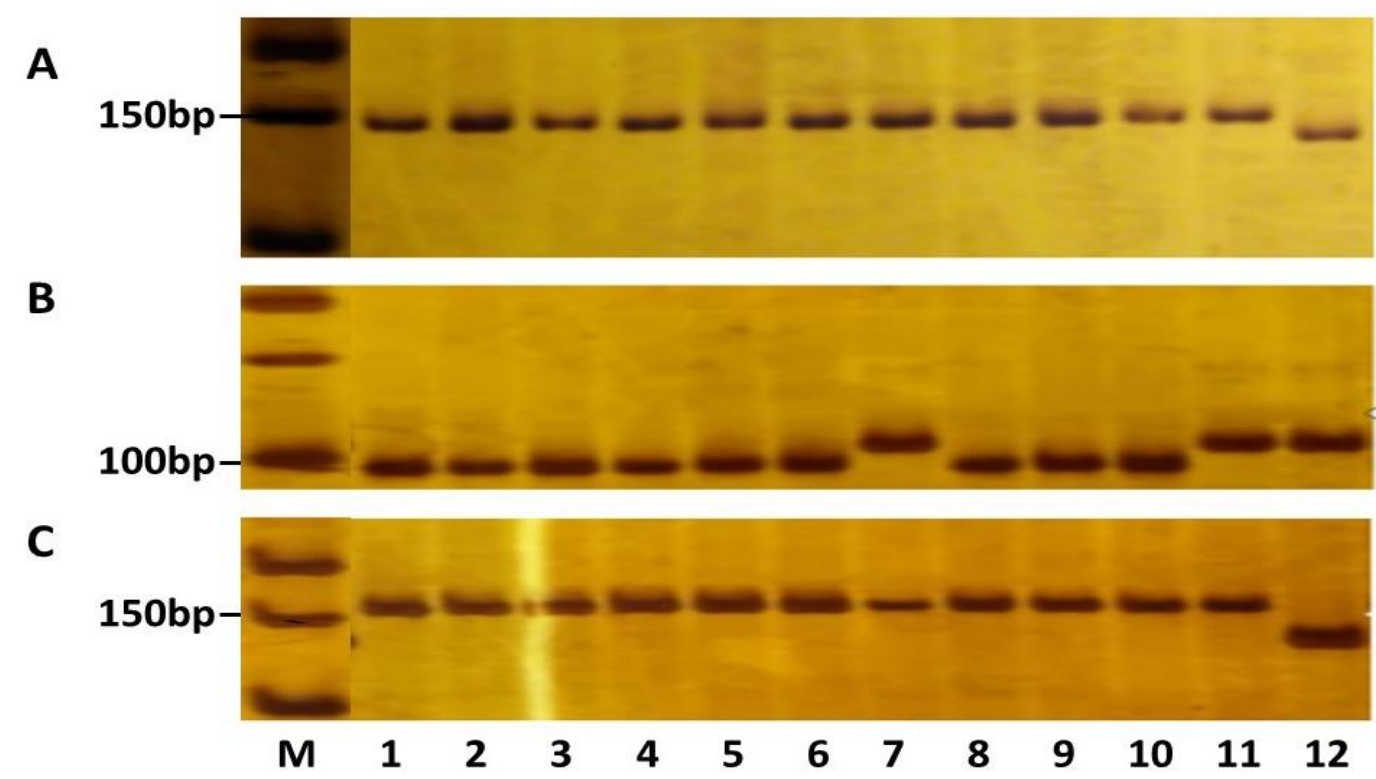

Figure 4 GW8 genotypic analysis of high quality xian/indica varieties

Note: M: DL500 DNA Marker; Lane 1 12: Ezhong 5, Yujing 91, Yuzhenxiang, Xiang5, 9311, 15Q340, R835, Huangmaozhan, Yangxizao, Huarun 2, Super-Basmati, Jianzhen 2; A: GW8-1; B:GW8-2; C: GW8-3

GS5 is a quantitative trait gene that controls grain width, fullness and thousand-grain weight on the $5^{\text {th }}$ chromosome of rice, encoding a serine carboxypeptidase. The two mutation sites of GS5 in ACC/CTA in the second exon and $\mathrm{A} / \mathrm{C}$ in the ninth exon make a significant difference to the grain length, grain width and $\mathrm{L} / \mathrm{W}$ Ratio of rice grains. Yi et al. (2016c) designed two CAPS markers, GS5-1 and GS5-2, based on these two sites. And according to these two mutation sites, the gene can be divided into 4 haploid genotype. GS5-1 can amplify a 225 bp PCR product, which be cut into 196 bp after Dde I digestion in CTA genotype, while cannot be cut in ACC genotype. And GS5-2 can amplify a 188 bp PCR product, which can be cut into 169 bp after Sal I digestion in C genotype, while cannot be cut in A genotype. The grain width of Hap2 of ACC-C in xian/indica subspecies is significantly larger than that of the other three haplotype. The results are shown in Figure 5. Among the 12 varieties, Yujing 91, Yuzhenxiang, 9311, R835, Huangmaozhan, and Yangxizao all have 225 bp and 169 bp bands, and the corresponding mutation sites are $\mathrm{ACC}$ and $\mathrm{C}$, which belong to the wide-grain haplotypeHap2. while the other 6 varieties show $225 \mathrm{bp}$ and $188 \mathrm{bp}$ bands, and the corresponding mutation sites are ACC and T, which belong to the narrow-grain haplotype Hap1.

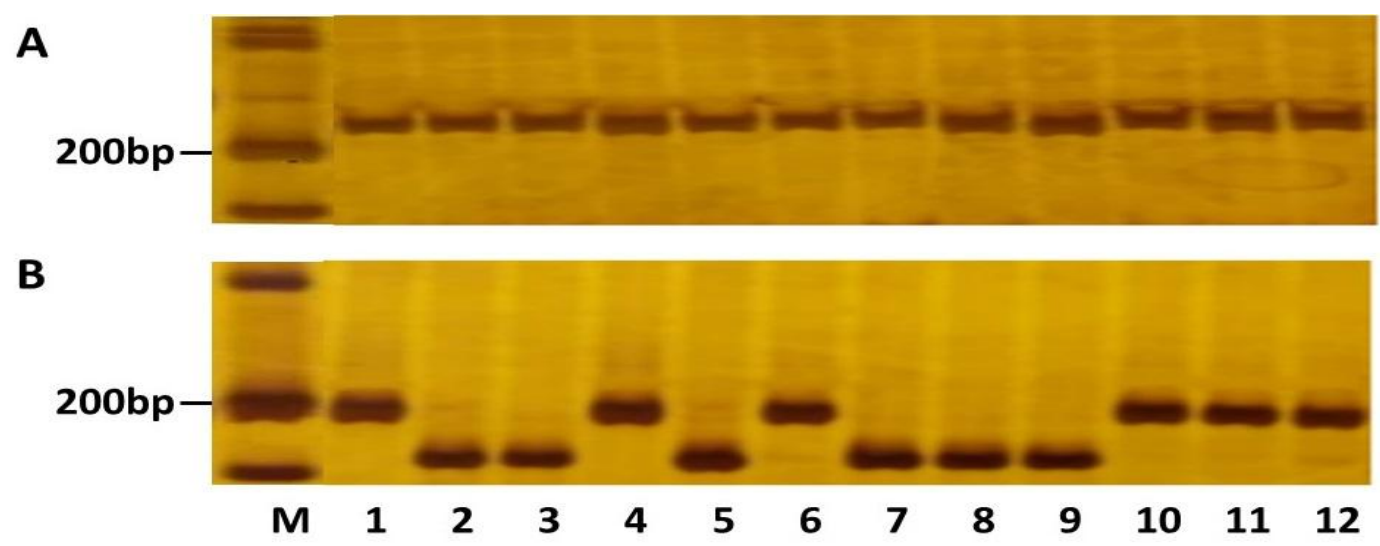

Figure 5 GS5 genotypic analysis of high quality xian/indica varieties(A:GS5-1; B:GS5-2)

Note: M, DL500 DNA Marker; Lane 1 12: Ezhong 5, Yujing 91, Yuzhenxiang, Xiang5, 9311, 15Q340, R835, Huangmaozhan, Yangxizao, Huarun 2, Super-Basmati, Jianzhen 2 


\subsection{Genotypic analysis of 10 grain shape genes in high quality xian/indica rice varieties}

Table 3 shows the genotypic analysis of 10 grain shape genes in 12 high quality xian/indica rice varieties.

In this study, molecular marker technology was used to identify and analyze the selected 12 high quality xian/indica rice varieties with 10 cloned genes which related to grain length and grain width. The test results are shown in Table 3. The results show that 12 high quality xian/indica rices all contain gs 3 long-grain allele; Ezhong No. 5, Yujing 91, Yuzhenxiang, Huangmaozhan, Yangxizao, Super Basmati and other 6 varieties contain GL7 and SLG7 long-grain alleles; 11 varieties except Jianzhen 2 contain $g w 8$ slender-grain allele; Yujing 91, Yuzhenxiang, 9311, R835, Huangmaozhan, Yangxizao contain GS5 wide-grain allele; The detected rice varieties don't contain $\operatorname{lgy} 3, q G L 3, T G W 6$ and $g s 9$ long-grain allele and don't contain $G W 5$ wide-grain allele.

Table 312 detected genes in high quality xian/indica varieties

\begin{tabular}{|c|c|c|c|c|c|c|c|c|c|}
\hline Accessions & $g_{s} 3$ & $\lg v 3 \quad q G L 3$ & GL7 & $S L G 7$ & TGW6 & $g_{S} 9$ & GW5 & $g w 8$ & $G S 5$ \\
\hline 9311(CK) & $\checkmark$ & & & & & & & $\checkmark$ & $\checkmark$ \\
\hline Ezhong 5 & $\checkmark$ & & $\checkmark$ & $\checkmark$ & & & & $\checkmark$ & \\
\hline Yujing 91 & $\checkmark$ & & $\checkmark$ & $\checkmark$ & & & & $\checkmark$ & $\checkmark$ \\
\hline Yuzhenxiang & $\checkmark$ & & $\checkmark$ & $\checkmark$ & & & & $\checkmark$ & $\checkmark$ \\
\hline Xiang 5 & $\checkmark$ & & & & & & & $\checkmark$ & \\
\hline $15 \mathrm{Q} 340$ & $\checkmark$ & & & & & & & $\checkmark$ & \\
\hline R835 & $\checkmark$ & & & & & & & $\checkmark$ & $\checkmark$ \\
\hline Huangmaozhan & $\checkmark$ & & $\checkmark$ & $\checkmark$ & & & & $\checkmark$ & $\checkmark$ \\
\hline Yangxizao & $\checkmark$ & & $\checkmark$ & $\checkmark$ & & & & $\checkmark$ & $\checkmark$ \\
\hline Huarun 2 & $\checkmark$ & & & & & & & $\checkmark$ & $\checkmark$ \\
\hline Super-Basimati & $\checkmark$ & & $\checkmark$ & $\checkmark$ & & & & $\checkmark$ & \\
\hline Jianzhen 2 & $\checkmark$ & & & & & & & & \\
\hline
\end{tabular}

\section{Discussion}

Traditional rice breeding methods are time-consuming, labor-intensive, and vulnerable to environmental influences. Molecular marker-assisted selection (MAS), as a new breeding method developed with the development of molecular biology and bioinformatics technology, has been widely used in major crop breeding practices because of its accuracy, speed, and no environmental influence. If conventional rice breeding technology is combined with MAS technology in the future, new high quality rice varieties can be cultivated more accurately and efficiently. Clarifying parent genotype and corresponding phenotype is the premise of using molecular marker-assisted selection. This study is helpful to establish an overall understanding of the genotypes of 10 grain shape genes in high quality xian/indica rice varieties, and provides important theoretical basis and genotype information in selecting and cultivating new high quality long-grain indica varieties via molecular marker-assisted selection in the future.

So far, according to incomplete statistics, more than 120 QTLs related to grain length of rice have been mapped. The statistical results show that the main QTLs controlling grain length are mainly located on the $3^{\text {rd }}$ chromosome and the $7^{\text {th }}$ chromosome (Han et al., 2016). The main genes controlling grain length on the $3^{\text {rd }}$ chromosome are mainly GS3 and $q G L 3$. Ding et al. (2014) showed that when only one of these two genes exists, it can show a strong phenotypic effect, but when they exist at the same time, there is no gene cumulative effect. Due to the limited distribution of $q G L 3$ gene in germplasm resource, the gene controlling grain length on the third chromosome is mainly the first cloned grain length gene GS3 in the existing bred varieties. Therefore, more studies are also focused on GS3 gene. Yang et al. (2010) improved the grain shape of rice by using a single fragment substitution line carrying gs 3 allele, which effectively improved the appearance quality of Huajingxian 74. Wang et al. (2012) introduced gs3 allele of 9311 into Zhenshan 97B. The grain length of Zhenshan 97B reached $9.2 \mathrm{~mm}$, increased by $10.8 \%$, and the thousand-grain weight was also increased. The appearance quality and yield were improved as well. Liu et al. (2018) found that the polymerization of $\lg y 3$ and $g s 3$ alleles increased the grain yield (about 7\%) and improved rice quality, providing a new strategy for breeding high-yield and high-quality rice. It can be seen from this study that 12 xian/indica rice varieties all contain the gs 3 allele, and the $g s 3$ allele has been widely used in the traditional empirical breeding of long-grain xian/indica rice. The reason is 
that $g s 3$ gene is the main gene and its parents are widely distributed. Both long-grain tropical japonica rice and long-grain xian/indica rice contain gs3 long-grain allele.

At present, the cloned grain shape genes not only cluster in a specific region of a chromosome, but also have more allelic forms at each locus, such as $q G L 3 / G L 3.1 / q G L 3-1$ on the third chromosome and $G L 7 / G W 7 / S L G 7$ on the $7^{\text {th }}$ chromosome. Gene sequence analysis showed that $G L 7$ has two copies of $G L 7$ alleles compared with g17, leading to the improvement of gene expression; The functional variation of $G W 7$ and $S L G 7$ is the same, but the difference of gene promoter leads to the difference of expression level; Cytological mechanism studies showed that GL7 and $G W 7$ act in the same way and increasing the vertical division of cells and decreasing the lateral division leads to slender grains. Studies on $S L G 7$ showed that increasing the vertical length of cells and decreasing the lateral width leads to slender grains, which is not related to cell division (Wang et al., 2015a; Wang et al., 2015b; Zhou et al., 2015). Although the results of different research groups indicate that the functional haploid genotype sites and regulatory mechanisms of $G L 7 / G W 7 / S L G 7$ are not completely the same, these three alleles all improve the expression level of gene $0 s 07 g 0603300$ and make the arrangement and structure of the starch grains of the rice grains changed. Moreover, these three alleles all lead to more slender rice grain, better color of rice grain, and improved appearance and taste of rice. If they aggregate $G L 7+g w 8$ or $g s 3+G W 7^{T F A}(S L G 7)$, slender grains can be shown (Wang et al., 2015a; Wang et al., 2015b).

In this study, we found that Ezhong No. 5, Yujing 91, Yuzhenxiang, Huangmaozhan, Yangxizao, Super Basmati and other 6 super-long-grain high quality xian/indica rice varieties from different sources contain allelic variation sites of $G L 7$ and $S L G 7 / G W 7$ simultaneously. That is, they have two copies of the GL7 gene and the functional site of the $S L G 7$ promoter at the same time, which showed that the functional loci of these three alleles are closely linked and may be the same allele in nature. Moreover, three long-grain gene loci ( $g_{s} 3, G L 7 / G W 7 / S L G 7$ and $g w 8$ ) are polymerized in the six super long-grain xian/indica varieties. Compared with general long-grain varieties such as 9311, only these super long-grain varieties have GL7/GW7/SLG7 allele. GL7/GW7/SLG7 gene is likely to be the main reason for these varieties to perform better than general ones. These six super long-grain xian/indica rice varieties not only taste good, but also show slender grains, good appearance and good physical and chemical quality. Among them, Ezhong No. 5, Yujing 91, and Yuzhenxiang have successively won the gold award of xian/indica rice group about the evaluation of eating quality of national high quality rice varieties. Super Basmati is the representative variety of high quality xian/indica rice in Southeast Asia. Huangmaozhan and Yangxizao are high quality local varieties in Hubei Province. Although the yield is low, due to the good appearance and eating quality, some enterprises still produce large areas at present. Although these varieties are not directly bred through MAS technology, they provide a theoretical and material basis for breeding high quality long-grain xian/indica rice by genotype selection of $G L 7 / S L G 7 / G W 7$ through MAS in the future. There are no long-grain alleles, $q G L 3$, $T G W 6$, and $g s 9$, in 12 high quality xian/indica rice varieties. It may be because of the low distribution frequency of these genes in rice germplasm. Using molecular marker technology for targeted selection will be beneficial to the use of these genes in breeding.

\section{Materials and Methods}

\subsection{Experimental materials and DNA extraction}

The rice materials used in this study were 12 high quality xian/indica rice varieties, including eight high quality conventional xian/indica varieties Ezhong 5, Yujing 91, Yuzhenxiang, Huangmaozhan, Yangxizao, Huarun 2, Jianzhen 2, Super Basmati, and four high quality xian/indica rice restorer lines Xiang 5, 9311, 15Q340, R835.

All rice materials were planted in the Nanhu Rice Experimental Base of Hubei Academy of Agricultural Sciences in 2018, and young leaves were taken for genomic DNA extraction.

\subsection{Determination of related data of rice grain shape}

The main panicle of selected plants were examined the grain shape after maturity stage. After the seeds were dried, 50 full grains randomly selected from each individual plant to measure the grain length, grain width and L/W ratio of each variety with a seed test instrument. The obtained data was statistically analyzed by Microsoft Excel 2010. 


\subsection{Gene detection of rice grain shape}

Referring to previous reports, the primers were synthesized to amplify 10 genes (Table 2), including GS3, $L G Y 3 / O s L G 3 b, q G L 3, G L 7, S L G 7 / G W 7, T G W 6$ and GS9, which control grain length, and including GS5, GW5 and $G W 8$, which control grain width. The primers were all synthesized by Wuhan Quintara Biological Company.

The PCR reaction system was $15 \mu \mathrm{L}$, containing $1.0 \mu \mathrm{L}$ template DNA $(50 \mathrm{ng} / \mu \mathrm{L}), 0.2 \mu \mathrm{L}$ Tag enzyme $(5 \mathrm{u} / \mu \mathrm{L})$, $1.50 \mu \mathrm{L} 10 \times$ Buffer $\left(\mathrm{Mg}^{2+}\right.$ plus $), 0.70 \mu \mathrm{L}$ each primer $(66 \mathrm{ng} / \mu \mathrm{L}), 0.8 \mu \mathrm{L} \mathrm{dNTPs}(2.5 \mathrm{mM} / \mu \mathrm{L})$, and making up to $15.00 \mu \mathrm{L}$ with $\mathrm{ddH}_{2} \mathrm{O}$. The PCR amplification procedure was as follows. Pre-denaturation was set at $95{ }^{\circ} \mathrm{C}$ for 5 min, and then there were 35 cycles of denaturation at $95^{\circ} \mathrm{C}$ for $30 \mathrm{~s}$, annealing for $30 \mathrm{~s}$ and extension at $72{ }^{\circ} \mathrm{C}$. Finally, amplified product were extended for $5 \mathrm{~min}$ at $72^{\circ} \mathrm{C}$ and stored at $4^{\circ} \mathrm{C}$.

Enzyme digestion system: $5 \mu \mathrm{L}$ of PCR amplified product was taken into the PCR tube. $1 \mu \mathrm{L}$ of the corresponding reaction buffer and $0.3 \mu \mathrm{L}$ of restriction enzyme were added, and then $\mathrm{ddH}_{2} \mathrm{O}$ was added to make up to $10 \mu \mathrm{L}$. Finally, we put it in $37^{\circ} \mathrm{C}$ water to bath for $3 \mathrm{~h}$ and it stopped reaction at $60^{\circ} \mathrm{C}$.

Electrophoresis detection: PAGE gel or agarose gel electrophoresis is used to detect the target band.

\section{Authors' contributions}

ZL and LEJ designed and executed the experiments, completed data analysis and wrote the first draft of the manuscript. XHS, CZJ, YGC and LK participated in designing the experiments and analyzing the results. ZL and YAQ conceived the project and was responsible for the project. And they directed the experiments, data analysis, paper writing and revision; All authors read and approved the final manuscript.

\section{Acknowledgements}

This study was jointly funded by Hubei Provincial Science and Technology Support Plan (2020ABA016, 2020BBB051), National Key Research and Development Project (2018YFD0301305, 2017YFD0100305) and National Rice Industry Technology System(CARS-01-78).

\section{References}

Ding D., Zhang Y.D., Zheng J., Zhao C.F., Chen T., Zhao Q.Y., Zhu Z., Zhou L.H., Yao S., Zhao L., Yu X., and Wang C.L., 2014, Design and application of functional markers of grain length genes GS3 and $q G L 3$ in rice, Jiangsu Nongye Xuebao (Jiangsu Journal of Agricultural Sciences), 30(6): 9-15

Fan C.C., Yu S.B., Wang C.R., and Xing Y.Z., 2009, A causal C-A mutation in the second exon of GS3 highly associated with rice grain length and validated as a functional marker, Theor. Appl. Genet., 118(03): 465-472

https://doi.org/10.1007/s00122-008-0913-1

PMid: 19020856

Gao Z.Q., Zhan X.D., Liang Y.S., Cheng S.H., and Cao L.Y., 2011, Progress on genetics of rice grain shape trait and its related gene mapping and cloning, Hereditas (Beijing), 33(4): 314-321

https://doi.org/10.3724/SP.J.1005.2011.00314 PMid:21482520

Han Y.S., Xu J., and Xiong H.Y., 2016, Correlation between length and quality of grain in Indica rice and its application in breeding, Guangdong Nongye Kexue (Guangdong Agricultural Sciences), 43(11): 1-6

Huang H.X., and Qian Q., 2017, Progress in genetic research of rice grain shape and breeding achievements of long-grain shape and good quality japonica Rice, Zhongguo Shuidao Kexue (Chinese Journal of Rice Science), 31(6): 665-672

Li H.K., Xu D.Z., and Chen Y.Y., 2005, Breeding of a new middle-indica rice variety Ezhong 5 with high quality, Hubei Nongye Kexue (Hubei Agricultural Sciences), 44(1): 31-32

Liu Q., Han R.,Wu K., Zhang J.Q., Ye Y.F., Wang S.S., Chen J.F., Pan Y.J., Li Q., Xu X.P., Zhou J.W., Tao D.Y., Wu Y.J., and Fu X.D., 2018, G-protein $\beta \gamma$ subunits determine grain size through interaction with MADS-domain transcription factors in rice, Nature Communications, $9(1): 852$ https://doi.org/10.1038/s41467-018-03047-9 PMid:29487282 PMCid:PMC5829230

Luo Y.K., Zhu Z.W., Chen N., Duan B.W., and Zhang L.P., 2004, Grain types and related quality characteristics of rice in China, Zhongguo Shuidao Kexue (Chinese Journal of Rice Science), 18(2): 135-139

Wan B.L., and You A.Q., 2018, Countermeasures of developing rice planting industry in Hubei Province, Nongye Keji Guanli (Management of Agricultural Science and Technology), 37(2): 56-59

Wang J., Yang J., Xu X., Zhu J.Y., Fan F.J., Li W.Q., Wang F.Q., and Zhong W.G., 2014, Development and application of a functional marker for grain weight gene TGW6 in Rice, Zhongguo Shuidao Kexue (Chinese Journal of Rice Science), 28(5): 473-478 
Wang P., Xing Y.Z., Li Z.K., and Yu S.B., 2012, Improving rice yield and quality by QTL pyramiding, Molecular Breeding, 29(4): 903-913 https://doi.org/10.1007/s11032-011-9679-2

Wang S.K., Li S., Liu Q., Wu K., Zhang J.Q., Wang S.S., Wang Y., Chen X.B., Zhang Y., Gao C.X., Wang F., Huang H.X., and Fu X.D., 2015a, The OsSPL16-GW7 regulatory module determines grain shape and simultaneously improves rice yield and grain quality, Nature Genetics, 47(8): 949-954 https://doi.org/10.1038/ng.3352 PMid:26147620

Wang Y.X., Xiong G.S., Hu J., Jiang L., Yu H., Xu J., Fang Y.X., Zeng L.J., Xu E.B., Xu J., Ye W.J., Meng X.B., Liu R.F., Chen H.Q., Jing Y.H., Wang Y.H., Zhu X.D., Li J.Y., and Qian Q., 2015b, Copy number variation at the GL7 locus contributes to grain size diversity in rice, Nature Genetics, 47(8): 944-949 https://doi.org/10.1038/ng. 3346 PMid:26147619

Weng, J., Gu, S., Wan, X. Gao H., Guo T., Su N., Lei C.L., Zhang X., Cheng Z.J., Guo X.P., Wang J.L., Jiang L., Zhai H.Q., and Wan J.M., 2008, Isolation and initial characterization of $G W 5$, a major QTL associated with rice grain width and weight. Cell Research, 18: 1199-1209 https://doi.org/10.1038/cr.2008.307 PMid: 19015668

Yang T.F., Zeng R.Z., Zhu H.T., Chen L., Zhang Z.M., Ding X.H., Li W.T., and Zhang G.Q., 2010, Effect of grain length gene GS3 in pyramiding breeding of rice, Fenzi Zhiwu Yuzhong (Molecular Plant Breeding), 8(1):67-74

Yi C.D., Li W., Wang D.R., Jiang W., Xue S., Geng J.P., Zhou Y., and Liang G.H., 2016a, Development and identification of functional marker for rice grain length gene $q G L 3$, Yangzhou Daxue Xuebao (Journal of Yangzhou University (Agricultural and Life Science Edition)), 37(4):55-59

Yi C.D., Wang D.R., Jiang W., Li W., Cheng X.J., Wang Y., Zhou Y., Liang G.H., and Gu M.H., 2016b, Development of functional markers and identification of haplotypes for rice grain shape gene GW8, Zuowu Xuebao (Acta Agronomica Sinica), 42(9): 1291-1297 https://doi.org/10.3724/SP.J.1006.2016.01291

Yi C.D., Wang D.R., Jiang W., Li W., Cheng X.J., Wang Y., Zhou Y., Liang G.H., and Gu M.H., 2016c, Development of functional markers and identification of haplotypes for rice grain width gene GS5, Zhongguo Shuidao Kexue (Chinese Journal of Rice Science), 30(5): 487-492

Yu J.P., Miao J.L., Zhang Z.Y., Xiong H.Y., Zhu X.Y., Sun X.M., Pan Y.H., Liang Y.T., Zhang Q., Rehman R.M. A., Li J.J., Zhang H.L., and Li Z.C., 2018, Alternative splicing of $O s L G 3 b$ controls grain length and yield in japonica rice, Plant Biotechnol. J., 16(9): 1667-1678 https://doi.org/10.1111/pbi.12903 PMid:29479793 PMCid:PMC6097128

Zhao D.S., Li Q.F., Zhang C.Q., Zhang C., Yang Q.Q., Pan L.X., Ren X.Y., Lu J., Gu M.H., and Liu Q.Q., 2018, GS9 acts as a transcriptional activator to regulate rice grain shape and appearance quality, Nature Communications, 9(1): 1240 https://doi.org/10.1038/s41467-018-03616-y PMid:29588443 PMCid:PMC5869696

Zhou Y., Miao J., Gu H.Y., Peng X.R., Leburu M., Yuan F.H., Gu H.W., Gao Y., Tao Y.J., Zhu J.Y., Gong Z.Y., Yi C.D., Gu M.H., Yang Z.F., and Liang G.H., 2015, Natural variations in SLG7 regulate grain shape in rice, Genetics, 201(4): 1591-1599 https://doi.org/10.1534/genetics.115.181115 PMid:26434724 PMCid:PMC4676533 